\title{
Recommendations for equitable COVID-19 pandemic recovery in Canada
}

\author{
Nav Persaud MD MSc, Hannah Woods MSc, Aine Workentin BSc, Itunu Adekoya MSc, James R. Dunn PhD, \\ Stephen W. Hwang MD MPH, Jonathon Maguire MD MSc, Andrew D. Pinto MD MPH, Patricia O'Campo PhD, \\ Sean B. Rourke PhD, Daniel Werb MSc PhD; for the MAP Task Force to Promote Health Equity during \\ Pandemic Recovery
}

Cite as: CMAJ 2021 December 13;193:E1878-88. doi: 10.1503/cmaj.210904

CMAJ Podcasts: author interview at www.cmaj.ca/lookup/doi/10.1503/cmaj.210904/tab-related-content

See related article at www.cmaj.ca/lookup/doi/10.1503/cmaj.211987

H ealth inequities - or avoidable differences in health status between populations - that were exposed and exacerbated during the COVID-19 pandemic can be addressed through interventions and policy changes that were studied before SARS-CoV-2 spread across Canada. ${ }^{1,2}$ Racialized people, women, people with a low income, people experiencing homelessness, people who use substances and people who are incarcerated were disproportionately affected during the pandemic. ${ }^{3-7}$ The pandemic revealed our interdependence as the spread of the virus among people experiencing disadvantages threatened the health of everyone, including those with privilege, and this has led to calls to address inequities under aphorisms such as "no one is protected until everyone is protected." 1

The current attention to inequities that have long persisted in Canada may fade as SARS-CoV-2 vaccinations roll out and the immediate harms of COVID-19 subside. Coordinated pandemic responses include efforts to return life to "normal" after the immediate threat, ${ }^{8}$ but the COVID-19 pandemic has underscored the need to address inequities rather than resume the unfair status quo. ${ }^{9}$ Income supports, eviction moratoria and other measures to mitigate harms of the pandemic have been temporarily implemented. ${ }^{10}$ We identified an opportunity to recommend interventions shown to promote health equity as part of longer term pandemic recovery.

\section{Scope}

The purpose of these recommendations is to address inequities that were exacerbated by the pandemic, and to inform pandemic recovery from a health equity perspective by making recommendations in the areas of income, housing, intimate partner violence, childhood, access to health care, and racism. The priority populations are those experiencing the selected inequities

\section{Key points}

- Inequities that were exposed and exacerbated by COVID-19 will continue to threaten health after the pandemic.

- Specific interventions and changes that relate to income, housing, safety from intimate partner violence, childcare, access to health care and antiracism are known to be beneficial.

- Implementing proven interventions and changes can promote health equity and protect health generally during the pandemic recovery and before the next pandemic.

- The effects of these interventions and changes on health equity should be carefully monitored to inform future changes in Canada and elsewhere.

regardless of their location in Canada (urban, rural or remote) and include new Canadians and migrants. The target audiences are decision-makers in the federal, provincial and municipal governments who set policies related to the inequities discussed, and health care providers who care for people experiencing disadvantage, especially primary care providers. The target audiences may use these recommendations to inform policy and clinical decisions.

The "pandemic recovery period" refers to the time when direct harms of COVID-19 subside; the recommended interventions and changes could be needed for months, years or permanently. Some changes could happen immediately.

The recommendations provide insights into the effectiveness of income assistance interventions for those who are affected by unemployment or low income; housing interventions for people experiencing homelessness or vulnerable housing; interventions for people experiencing intimate partner violence; interventions to address childhood health equity; interventions to improve access to health care; and ways to address racism and health. 


\section{Recommendations}

We make 13 recommendations based on findings from systematic reviews to address health inequities related to income, housing, intimate partner violence, childhood, access to health care, and racism. The grading of the recommendations is explained in Box 1. Box 2 and Figure 1 summarize the recommendations for the pandemic recovery period.

\section{Income}

We strongly recommend cash transfers ensuring a living income that allows people to afford basic necessities such as food (moderate certainty in estimates).

Cash transfers improve some health outcomes such as the likelihood of having had any illness, according to a systematic review of 21 studies, including 16 trials, 4 observational studies and 1 cohort study, done in low- and middle-income countries (odds ratio [OR] $0.73,95 \%$ confidence interval [Cl] 0.57 to 0.93 ) (Appendix 1, section 1A, available at www.cmaj.ca/lookup/ doi/10.1503/cmaj.210904/tab-related-content). ${ }^{12}$ A recent evaluation of a living income in Finland found improvements in mental well-being and improved financial security. ${ }^{13}$ Some have raised concerns that a living income could reduce motivation to work, but the opposite was observed in Iran and Finland. ${ }^{13,14}$ Several older studies, such as the 1970s Manitoba Basic Annual Income Experiment (Mincome) study, show benefits of a living income that include reduced hospital admissions and increased high school graduation rates. ${ }^{15} \mathrm{~A}$ recent observational study of monthly $\$ 500$ cash transfers for 2 years to individuals with a low income in Stockton, California, found increased employment, reductions in debt load and improvements in some measures of mental health (https://socialprotection.org/discover/publications/ preliminary-analysis-seed's-first-year). ${ }^{16} \mathrm{~A}$ recent small trial of a single cash transfer to individuals experiencing homelessness in Vancouver, British Columbia, found reductions in the number of days homeless. ${ }^{17}$ Cash transfers would likely be acceptable to beneficiaries and the public, according to an opinion poll. ${ }^{18}$

An Ontario pilot project on basic income was started in 2018 to investigate effects of providing a living income in Canada that was sufficient for essentials such as food. ${ }^{19}$ The cost of a program will depend on the size of the transfer. Indices such as market-based measures show that essentials cost about $\$ 2000$ per month per

\section{Box 1: Grading of recommendations ${ }^{11}$}

- "Strongly recommend" means that the benefits of an intervention or change clearly outweigh any negative effects. Widespread implementation may be warranted now.

- "Recommend" means that benefits of an intervention or change outweigh any negative effects. Initial implementation could be evaluated, as the net benefit may vary.

- The parenthetical statement about certainty in effect estimates (high, moderate, low or very low certainty in effect estimates) in the recommendations refers to our assessment of how well the findings from included studies reflect the true effects of the intervention or change. adult, but the necessary amount varies based on rurality and jurisdiction. ${ }^{20}$ One potential approach would be for the federal government to provide the lowest amount needed in Canada and for provinces and territories to "top up" that amount. The Parliamentary Budget Office has estimated that guaranteeing an income of $\$ 16989$ for every adult would reduce poverty rates by $49 \%$ at a cost of about $\$ 85$ billion annually in $2022 .{ }^{21}$

Box 2: Summary of recommendations during the pandemic recovery period

\section{Income}

- We strongly recommend cash transfers ensuring a living income that allows people to afford basic necessities such as food (strong recommendation; moderate certainty in estimates).

- We strongly recommend the universal availability of unemployment insurance, parental leave and paid sick leave (strong recommendation; low certainty in estimates).

- We recommend affordable credit or loans for low-income individuals (recommendation; very low certainty in estimates).

\section{Housing}

- We strongly recommend the expansion of permanent supportive housing programs with high fidelity to the Housing First approach, which entails assertive engagement and case management, less than $30 \%$ of income spent on housing, the choice of housing, and the choice of supportive services without coercion to participate for individuals with serious mental health problems or who use substances and are experiencing homelessness (strong recommendation; high certainty in estimates).

- We recommend expanding access to eviction prevention interventions, including access to legal services and financial advice (recommendation; very low certainty in estimates).

\section{Intimate partner violence}

- We strongly recommend interventions that include legal advocacy and supportive interventions for victims of intimate partner violence (strong recommendation; moderate certainty in estimates).

\section{Childhood}

- We recommend the expansion of publicly funded childcare (recommendation; low certainty in estimates).

- We recommend healthy food distribution to children (recommendation; moderate certainty in estimates).

\section{Access to health care}

- We recommend expanding access to opioid substitution therapy and supervised injection sites (recommendation; moderate certainty in estimates).

- We recommend expanding screening for HIV and hepatitis C virus among individuals at high risk (recommendation; moderate certainty in estimates).

- We recommend improving the health care of people who are incarcerated (recommendation; low certainty in estimates).

- We strongly recommend including prescription medicines in Canada's publicly funded health care system (strong recommendation; moderate certainty in estimates).

Racism

- We strongly recommend reflection and action on multiple prior reports that outlined approaches to addressing anti-Indigenous discrimination, anti-Black racism and other manifestations of racism (ungraded statement). 


\section{Equitable COVID-19 pandemic recovery in Canada}

\section{Problem:}

Inequities that worsened

during the pandemic will

continue to threaten health
Solution:

Policy changes at the federal, provincial and municipal levels

to promote health equity

\section{Recommendations}

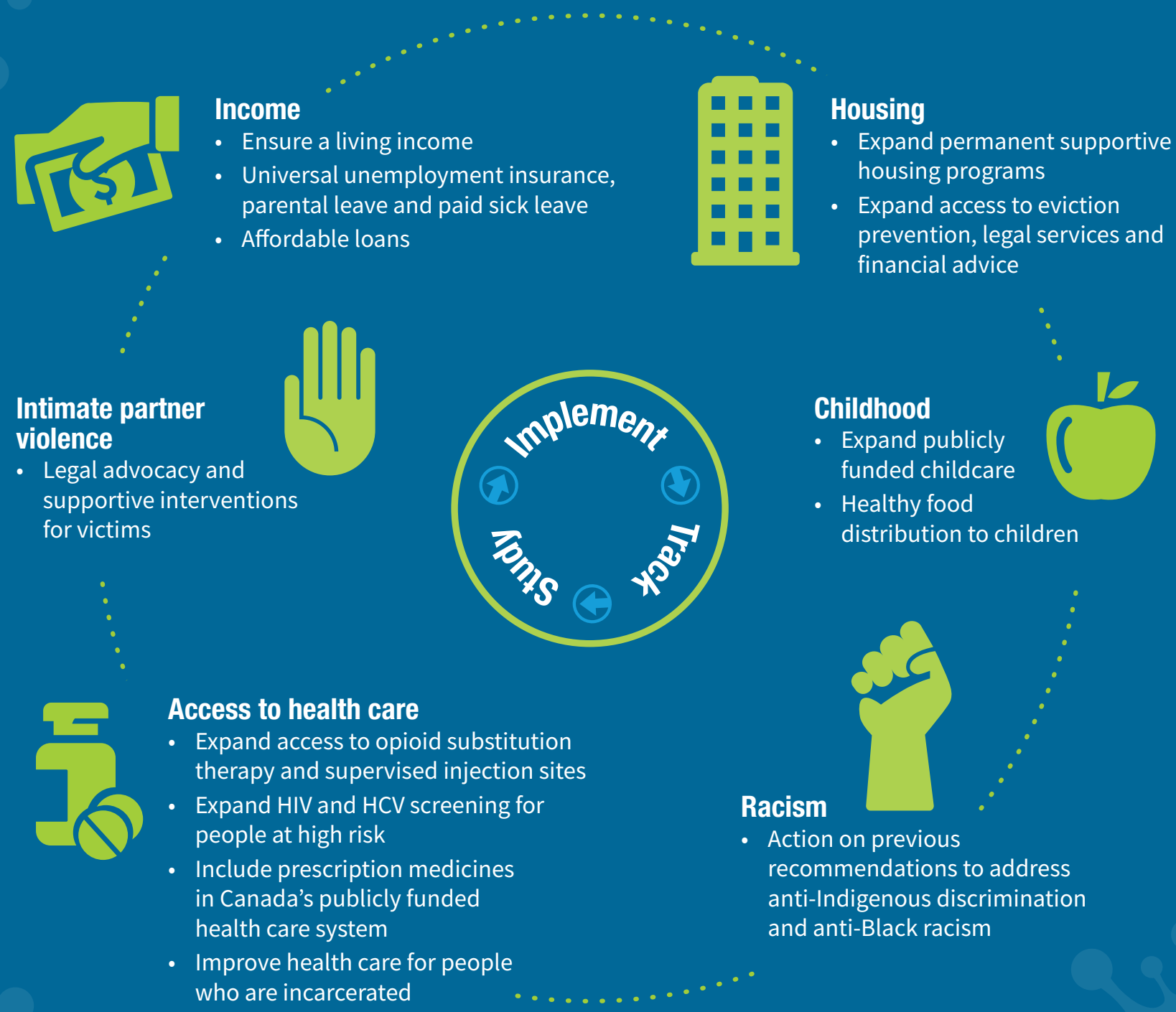

Figure 1: Guideline overview with summary of recommendations. Note: HCV = hepatitis C virus. 
We strongly recommend the universal availability of unemployment insurance, parental leave and paid sick leave (low certainty in estimates).

Supports that protect the income of workers when active employment is interrupted improve self-reported health, mental health and well-being, according to a systematic review of 12 observational studies ${ }^{22}$ (e.g., odds of poor selfreported health $3.04,95 \% \mathrm{Cl} 2.45$ to 3.77 for unemployed with basic allowance v. $1.25 ; 95 \% \mathrm{Cl} 0.89$ to 1.75 for those with earning-related employment insurance; reference group is employed individuals for both ${ }^{23}$ ) (Appendix 1, section 1B). Losing employment is associated with poor health, and unemployment insurance seems to mitigate the harms of unemployment. ${ }^{24}$ Observational studies found that unemployment insurance slightly slowed the return to work. ${ }^{22}$ Paid parental leave improves maternal and child health outcomes, including neonatal mortality, according to observational studies in high-income countries. ${ }^{25,26}$ Paid sick leave reduces the spread of infectious diseases and reduces stress. ${ }^{27}$ Expansions of unemployment insurance during the pandemic were widely supported, ${ }^{28}$ and it is likely to be supported in the future.

The eligibility criteria for unemployment insurance were relaxed during the pandemic period, and this could be extended during the pandemic recovery period. Unemployment schemes that already exist at the federal, provincial and territorial levels can be expanded and eligibility criteria can be simplified. The durations of paid parental leave can be extended. Paid sick leave is currently determined by employers in most jurisdictions; however, this can be made a standard part of employment because all workers can get sick. These supports may be needed in addition to a universal living income.

We recommend affordable credit or loans for low-income individuals (very low certainty in estimates).

Affordable credit and small loans, with no or low interest rates, improve a variety of health outcomes for women and children, according to a systematic review of 1 trial and 22 quasi-experimental studies done in low- and middle-income countries $^{29}$ (e.g., infant mortality OR $0.78,95 \% \mathrm{Cl} 0.68$ to $0.90^{30}$ ) (Appendix 1, section 1C). Some studied interventions of microfinance (small loan) programs involved co-interventions such as health education. ${ }^{31}$ Although these interventions were developed in rural low-income settings, they have been implemented in urban high-income settings such as Queens, New York, United States. ${ }^{32}$ Microfinancing operates on the theory that low-income individuals may benefit from access to credit that is traditionally available to others but not to them. Qualitative studies in specific populations show that microfinance programs are acceptable to recipients. ${ }^{33}$

The use of "payday loans," small and high-interest loans that should be paid off quickly, was common in Canada before the pandemic. ${ }^{34,35}$ In other countries, small loans are offered by nongovernmental organizations with government support, and such a model could work in Canada. ${ }^{36}$

\section{Housing}

We strongly recommend the expansion of permanent supportive housing programs with high fidelity to the Housing First approach, which entails assertive engagement and case management, less than $30 \%$ of income spent on housing, the choice of housing, and the choice of supportive services without coercion to participate for individuals with serious mental health problems or who use substances and are experiencing homelessness (high certainty in estimates).

Permanent supportive housing improves long-term ( $>5 \mathrm{yr}$ ) housing stability for people with serious mental illness or who use substances, according to a systematic review of 15 trials of permanent supportive housing (relative risk of 6 -yr housing stability $1.42,95 \%$ $\mathrm{Cl}$ 1.19-1.69) (Appendix 1, section 2A). ${ }^{37}$ Another systematic review identified similar benefits. ${ }^{38}$ Randomized controlled trials (RCTs) conducted in Canada and the US showed substantial benefits and limited or no harms. ${ }^{37}$ The fidelity of interventions to the Housing First intervention, based on the Pathways Housing First Fidelity Scale, is associated with housing stability. ${ }^{39}$ Qualitative studies support the acceptability of permanent supportive housing. ${ }^{40,41}$

During the pandemic recovery period, risks associated with homelessness will continue to be a serious threat to health, and the prevalence of homelessness will likely be substantial for individuals with serious mental illness. Expanding access to permanent supportive housing during the pandemic recovery period should substantially increase the number of people with serious mental illnesses who are stably housed in the coming years. Permanent supportive housing in general, and the Housing First intervention in particular, are cost-effective. ${ }^{42}$

We recommend expanding access to eviction prevention interventions, including access to legal services and financial advice (very low certainty in estimates).

Supports aimed at preventing evictions, including financial advice about how to address rent arrears and services from a paralegal or lawyer, can reduce the risk of being served with an eviction notice, according to a systematic review of 3 studies, including 1 trial and 2 observational studies. ${ }^{43}$ For example, an RCT of individuals queuing up at a housing court in New York City to handle rent arrears found that free legal assistance reduced the risk of an eviction warrant being served (relative risk 0.43, $95 \% \mathrm{Cl} 0.30$ to 0.61 ) (Appendix 1, section 2B). ${ }^{44}$ Eviction prevention is likely acceptable to recipients, as 1 trial indicated a similar number of court appearances but better outcomes. ${ }^{44}$

Keeping people in their current home is a straightforward way to reduce the number of people experiencing homelessness. The pandemic has made it more difficult for individuals to navigate government programs, as the programs proliferated with evolving eligibility criteria and supports for individuals applying have been disrupted. Legal representation of tenants can help keep people housed and reduce the costs associated with dispute resolution and rent nonpayment, for both tenants and landlords. ${ }^{45}$

\section{Intimate partner violence}

We strongly recommend interventions that include legal advocacy and supportive interventions for victims of intimate partner violence (moderate certainty in estimates). 
Legal advocacy and other supportive interventions, such as education and counselling for victims of intimate partner violence, reduce the likelihood of physical abuse in some contexts, reduce the risk of depression, and improve well-being, according to a systematic review of 13 trials (e.g., brief advocacy reduced minor physical abuse at 1 year, mean difference [MD] $-1.0,95 \%$ $\mathrm{Cl}-1.8$ to -0.2 ; intensive advocacy improved quality of life for women living in shelters, MD $0.23,95 \% \mathrm{Cl} 0.00$ to 0.46 ) (Appendix 1 , section $3 \mathrm{~A}) .{ }^{46}$ No harms were identified in the studies but concerns about advocacy precipitating violence is a potential barrier. ${ }^{47}$ Such interventions are acceptable to recipients, especially when coordinated with other needed services. ${ }^{48}$

Expanding and ensuring access to legal advocacy may have health benefits outside of addressing intimate partner violence, including improved housing and income. ${ }^{49}$ Timely and easy access to legal advocacy without out-of-pocket costs will be important for people seeking support. Interventions that promote the ability of victims of intimate partner violence to remain in their home, such as the safe-at-home model, have been piloted in other countries and can be evaluated in Canada. ${ }^{50}$

Supports related to addiction and trauma for perpetrators of violence against women also reduce the likelihood of violence, according to a systematic review of 17 observational studies. ${ }^{51}$ These observational studies, in mostly high-income countries, found that group therapy was associated with reductions in violence. Implementing interventions for perpetrators, together with interventions for victims, may help to reduce the risk of violence against women during the pandemic recovery period (Appendix 1, section $3 \mathrm{C}$ ).

\section{Childhood}

We recommend the expansion of publicly funded childcare (low certainty in estimates).

Childcare may improve the cognitive development of children younger than 5 years, according to 2 systematic reviews in highand low-income countries that each included 1 trial (cognitive development standardized MD $0.74,95 \% \mathrm{Cl} 0.48$ to 1.00 in lowand middle-income countries ${ }^{52} ; 0.34,95 \% \mathrm{Cl}-0.01$ to 0.69 in high-income countries ${ }^{53}$ ) (Appendix 1, section 4A). Other benefits include increased parental employment. ${ }^{54}$ Publicly funded childcare would likely be highly acceptable to families, especially to parents who wish or need to work. ${ }^{55}$

The number of childcare staff and facilities will need to be increased substantially to accommodate expected increases in childcare enrolment. Provision of childcare was cost-saving when benefits until age 40 years were considered for Black children included in the HighScope Perry Preschool Program, which was started in 1962 in Michigan. ${ }^{56}$

We recommend healthy food distribution to children (moderate certainty in estimates).

Food distribution increases physical growth and psychomotor development in children younger than 5 years, according to a systematic review of 21 trials that were mostly conducted in low- and middle-income countries (weight increase over 6 months $0.12 \mathrm{~kg}$, 95\% $\mathrm{Cl} 0.05$ to 0.18 ; psychomotor development standardized MD $0.41,95 \% \mathrm{Cl} 0.10$ to 0.72 ) (Appendix 1 , section 4B). ${ }^{57}$ Other studies in high-income countries identified similar benefits, which were dependent on the context, such as time during the day that food was served and the type of supervision during food provision. ${ }^{58}$

Use of food banks and food insecurity in Canada were common even before the pandemic. ${ }^{59}$ Food distribution at school can help improve attendance. ${ }^{60}$ The selection of foods should be based on the dietary needs of children and not which foods are available or have been donated.

\section{Access to health care}

We recommend expanding access to opioid substitution therapy and supervised injection sites (moderate certainty in estimates).

Opioid substitution for opioid use disorder among general populations is associated with reductions in nonprescribed opioid use, according to a systematic review of 11 trials (relative risk $0.66,95 \% \mathrm{Cl}$ 0.56 to 0.78 ) (Appendix 1, section $5 A$ ). ${ }^{61}$ Supervised injection sites reduce overdose and promote access to care (e.g., 35\% reduction in fatal overdoses in immediate area surrounding supervised injection site), ${ }^{62}$ and medical treatment may reduce harms. ${ }^{63} \mathrm{~A}$ meta-analysis of 28 observational studies found that opioid substitution treatment is associated with a $50 \%$ reduction in the risk of new hepatitis $C$ virus (HCV) infections among people who inject drugs (risk ratio 0.50, 95\% $\mathrm{Cl} 0.40$ to 0.63$).{ }^{64}$ The combined use of high-coverage needle syringe programs with opioid substitution treatment is associated with a $74 \%$ reduction in risk of $\mathrm{HCV}$ infection (risk ratio $0.26,95 \% \mathrm{Cl} 0.07$ to 0.89). ${ }^{64}$ Multiple studies show that opioid substitution therapy is costeffective and acceptable. ${ }^{65,66}$ Support for supervised injection varies, although many Canadians know someone who might benefit. ${ }^{67}$

The pandemic and related disruptions in health care and social services, combined with social and economic stressors, have likely contributed to the worsening epidemic of opioid toxicity. ${ }^{68,69}$ Expanding access to opioid substitution therapy and supervised injection sites could lessen the effect of the pandemic on overdoses, but also have lasting effects by reducing existing barriers to proven treatments in the long run. These measures can be coupled with others aimed at protecting a safe drug supply, reducing the stigmatization and criminalization of people who use substances, and reducing harms of substance use. ${ }^{70}$

We recommend expanding screening for HIV and HCV among individuals at high risk (moderate certainty in estimates).

The pandemic has decreased access to HIV screening services; testing volumes decreased for reasons such as testing site closures during lockdown, reduced numbers of staff, reduced attendance and fewer appointments scheduled, laboratories overburdened and fewer referrals to the facility. ${ }^{71}$ Expanding access to screening for HIV and HCV among individuals at high risk may help to reduce the long-term harms of pandemicrelated disruptions. Rapid voluntary counselling and testing increases uptake (relative risk $2.95,95 \% \mathrm{Cl} 1.69$ to 5.16 ) and receipt of results (relative risk $2.14,95 \% \mathrm{Cl} 1.08$ to 4.24 ), compared with conventional testing, according to a systematic review of 8 trials and 5 observational studies (Appendix 1 , section 5B). ${ }^{72}$ Screening for HIV and HCV is recommended for individuals at high risk, including people who use drugs. ${ }^{73}$ Harms of screening may include stigmatization and adverse effects of treatments 
that are overall beneficial. ${ }^{72,74}$ Screening has been shown to be acceptable to patients, according to a scoping review of HIV selftesting that included qualitative studies and trials. ${ }^{74}$

The expansion of screening programs is likely to be costeffective, according to a systematic review of 26 observational studies. $^{76}$

We recommend improving the health care of people who are incarcerated (low certainty in estimates).

Opioid substitution treatment during incarceration reduces opioid use and increases engagement in care, according to a systematic review of 22 trials and 21 observational studies ${ }^{77}$ (e.g., positive urine opioid test $66 \%$ in control v. $25 \%$ with methadone; mean number of days in treatment over year $23 \mathrm{~d}$ for control v. $166 \mathrm{~d}$ for methadone ${ }^{78}$ ) (Appendix 1, section 5C). The benefits of opioid maintenance therapy provided in prison, such as reductions in heroin use and associated risk behaviours, are consistent with evidence of the effectiveness of opioid maintenance therapy in community settings. ${ }^{79}$ Pharmacologic interventions have positive impacts on postrelease mortality, substance use, treatment adherence and criminogenic outcomes if treatment is administered during incarceration and continued upon release. ${ }^{79}$ Providing opioid substitution therapy to people who are incarcerated is likely acceptable and cost-effective..$^{80,81}$

There have been lower rates of testing for SARS-CoV-2 infection in prison facilities than in the community, even though incarcerated individuals are at increased risk; high rates of SARSCoV-2 infections among the incarcerated population have been observed. ${ }^{7}$ This suggests an opportunity to match the provision of health care generally to the needs of people who are incarcerated, although we did not identify studies addressing the general provision of health care in this population.

We strongly recommend including prescription medicines in Canada's publicly funded health care system (moderate certainty in estimates).

Eliminating or reducing out-of-pocket medicine costs borne by patients improves adherence and reduces health care utilization, according to a systematic review of 23 observational studies $^{82}$ (e.g., increased inpatient care use after exceeding insurance limits, relative risk $1.85,95 \% \mathrm{Cl} 1.64$ to $2.09^{83}$ ) (Appendix 1 , section 5D). A clinical trial in which medicines were distributed to primary care patients in Ontario who could not afford medicines found improved adherence and decreased health care costs. ${ }^{84}$ Results of a nationally representative survey show that public funding of medicines would be widely accepted. ${ }^{85}$

The pandemic exposed a vulnerability in tying medicine access to employment, via either employer-based private insurance or the ability to pay for medicines out of pocket when millions of people in Canada lost their jobs or saw their income drop. ${ }^{86}$ Racialized people were disproportionately affected. ${ }^{85}$ After a 2018 parliamentary committee report titled Pharmacare Now, the National Advisory Council on the Implementation of National Pharmacare studied implementing national pharmacare, or including medicines in Canada's publicly funded health care system. ${ }^{87,88}$ The Parliamentary Budget Office estimated that implementing pharmacare would save about $\$ 4$ billion per year. ${ }^{89}$

\section{Racism}

We strongly recommend reflection and action on multiple prior reports that outlined approaches to addressing anti-Indigenous discrimination, anti-Black racism and other manifestations of racism (ungraded statement).

Before the COVID-19 pandemic, multiple reports documented the harmful effects of racism, including anti-Black and antiIndigenous discrimination, and provided recommendations. Because racism affects health, recommendations in multiple documents spanning a wide range of issues are relevant to health equity ${ }^{90-93}$ (Appendix 1, section 6). Our recommendation is an ungraded statement based on the importance of the issue, the high likelihood of benefit and support from a vast body of indirectly related information. ${ }^{94}$ Reflection on previous reports is needed to understand why little action was taken despite previous commitments to addressing racism.

The 1996 Royal Commission on Aboriginal Peoples made more than 100 recommendations that spanned issues from supports for children and youth to the treatment of older adults. ${ }^{95}$ In 2014, the UN Special Rapporteur on the rights of Indigenous peoples made 15 recommendations in the following categories: social and economic conditions, truth and reconciliation, missing women and girls, self-government, participation and partnership, treaty negotiation and claims processes, and resource development. ${ }^{96}$

To repair the legacy of residential schools and move forward with reconciliation, in 2015, the Truth and Reconciliation Commission made 94 calls to action in the areas of child welfare, education, language and culture, health, justice, the United Nations Declaration on the Rights of Indigenous Peoples, proclamation and covenant of reconciliation, settlement agreements, equity in the legal system, national council for reconciliation, professional development and training, church apologies, youth programs, museums and archives, missing children and burial information, commemoration, media, sports, business and newcomers to Canada. ${ }^{95}$ In 2019, the Final Report of the National Inquiry into Missing and Murdered Indigenous Women and Girls made 231 calls for justice, directed at governments, institutions, social service providers, industries and all Canadians, for transformative legal and social changes to resolve the national crisis. ${ }^{97}$ Four pathways to be addressed were presented: historical, multigenerational and intergenerational trauma; social and economic marginalization; maintaining the status quo and institutional lack of will; and ignoring the agency and expertise of Indigenous women, girls and Two Spirit, lesbian, gay, bisexual, transgender, queer, questioning, intersex and asexual (2SLGBTQQIA) people. ${ }^{97}$

The 2017 report of a United Nations Human Rights working group made 15 recommendations related to addressing anti-Black racism in the criminal justice system; hate crimes; education, health, housing and employment; and intersecting forms of discrimination. ${ }^{98} \mathrm{~A} 1992$ report to the Premier of Ontario about antiBlack racism made 23 recommendations and noted the need to act on recommendations from earlier decades, and even "bewilderment" that some previously recommended changes had not been implemented. ${ }^{99}$ Multiple reports have focused on racism in health care, including those compiled by Well Living House. ${ }^{100}$ 
Despite past recommendations, systemic racism has led to disproportionate effects of the pandemic on racialized people, reflected in higher rates of SARS-CoV-2 infections and deaths.,101 Racism is not new; nor are proclamations about the need to address racism urgently. The pandemic recovery period would be an appropriate time to act on previous recommendations related to addressing racism that can promote health.

\section{Methods}

We used the Grading of Recommendations Assessment, Development and Evaluation (GRADE) approach to developing recommendations and followed the Appraisal of Guidelines for Research and Evaluation (AGREE II) reporting guidance. ${ }^{11,102}$

\section{Recommendations panel composition}

The MAP Centre for Urban Health Solutions is a research centre that focuses on health equity. It is based at St Michael's Hospital in Unity Health Toronto and is affiliated with the University of Toronto. Given the specific focus of the centre, we established the recommendations panel by sending email invitations to all centre scientists starting in August of 2020; 8 of 28 (29\%) decided to participate. Members on our panel have expertise in implementation science, income, housing, health services, primary care and discrimination.

We engaged members of the public $(n=4)$ - including those with relevant lived experience related to health inequities - on the topics and recommendations, through 2 teleconference meetings in August of 2020 and February of 2021.

\section{Topic selection}

An initial list of topics was developed (by N.P.), based on known reports about health inequities in Canada ${ }^{1,103,104}$ and discussions with people with lived experience of disadvantage, and circulated via an online survey to all centre scientists $(n=28)$, who were invited to suggest additional topics or to revise suggested ones ( $n=7[25 \%]$ responded).

The final topics were then selected during a meeting of the recommendations panel, and 6 topics (income, housing, intimate partner violence, childhood, racism and access to health care [comprising 4 subtopics]) were selected by consensus, with consideration of the contribution of each factor to avoidable inequities in health outcomes. We conducted preliminary literature searches for all suggested topics but decided not to proceed with some.

\section{Literature review}

We developed literature searches for populations, interventions, comparators and outcomes selected for each topic, in consultation with a health sciences librarian. We (H.W., A.W. and I.A.) searched Ovid MEDLINE for peer-reviewed systematic reviews that focused on health outcomes, published in English between Jan. 1, 2000, and Feb. 1, 2021. One reviewer (H.W., A.W. or I.A.) determined whether each systematic review was relevant, and this determination was confirmed or questioned by a second reviewer. Disagreements were resolved through discussion or by consulting a third reviewer (H.W., A.W., I.A. or N.P.). We performed separate searches for preferences and values related to each topic.

\section{Development of recommendations}

Evidence-to-decision frameworks were created for each topic (Appendix 1, sections 1-6). ${ }^{105}$ The recommendations panel members reviewed these and drafted recommendations, taking preferences and values into account, as determined by dedicated literature searches.

The recommendations panel met during a series of virtual meetings in January and February of 2021 (on Jan. 6, Jan. 13, Jan. 27, Feb. 10 and Feb. 24) to determine the final recommendations, the strength of each recommendation and the certainty in the effect estimates by consensus. As per guidance from GRADE, we made strong ("we strongly recommend") and weak ("we recommend") recommendations, and we separated decisions about the strength of recommendations from decisions about our certainty in the effect estimates. ${ }^{11}$ For one topic (racism), we decided to make an ungraded statement because of the importance of the issue, the high likelihood of benefit and support from a vast body of indirectly related information. ${ }^{94}$ All recommendations were developed by consensus and voting was not necessary.

\section{External review}

We shared draft recommendations with individuals with lived experience $(n=4)$, selected decision-makers $(n=3)$ and national bodies related to clinical practice and public health $(n=19$; Appendix 1, section 7D), for wider input from stakeholders with different perspectives. We sought comments using open-ended questions and incorporated suggestions after the recommendations panel had reviewed them. Changes based on external review included revisions of recommendation wording and changes to the supporting text, including implementation issues.

\section{Management of competing interests}

We handled competing interests in line with Guidelines International Network principles, at the direction of an external conflictof-interest oversight committee. ${ }^{106}$ The recommendations panel comprised individuals who were free of direct conflicts of interests, as per guidance. ${ }^{107}$ Panel members were asked to declare potential competing interests, including indirect competing interests; the panel was made up of individuals with different areas of interest, which limited any effect of intellectual conflicts of interest. ${ }^{107}$

\section{Implementation}

The MAP Centre for Urban Health Solutions maintains a document detailing the support for the recommendations on its website (maphealth.ca). We will maintain a list of related resources, based on suggestions from consulted stakeholders, with the guideline. We have shared the guideline with key decisionmakers at the federal, provincial and municipal levels (Appendix 1, section 7D).

The current public attention to inequities during the pandemic, coupled with the Government of Canada's commitment to reducing poverty by $50 \%$ by 2030 , could facilitate lasting changes. ${ }^{108}$ Barriers to implementing changes include waning attention to inequities as the direct risks of the pandemic abate for most Canadians, the influence of those who benefit from the 
inequitable status quo (e.g., companies that profit from the exclusion of medicines from publicly funded health care), and a desire to move on after the pandemic.

The recommendations must be implemented equitably. For example, initiatives to improve access to permanent supportive housing should address other inequities, such as racism. We plan to elaborate on some recommendations with additional details about implementation in collaboration with others, including organizations that provide relevant services and are engaged in advocacy on these issues.

We plan to revisit the value of updating these recommendations in 3 years' time and post updates on www.maphealth.ca. Progress in implementing these recommendations can be tracked through poverty rates; the number of loans provided to individuals with a low income; the proportion of individuals with serious mental health problems who lack permanent supportive housing; overall housing rates; eviction rates; rates of intimate partner violence; supports provided to people experiencing intimate partner violence; the number of children in childcare; food security among children; opioid-related mortality rates; utilization rates for opioid substitution therapy and supervised injection sites; HIV and HCV incidence and burden; health and health care access for people who are incarcerated; cost-related nonadherence to medicines; health outcomes (including mortality) for racialized people relative to others; and progress toward implementing previous recommendations related to anti-Indigenous discrimination and other forms of racism. Tracking could be done by federal, provincial and territorial agencies, such as the Public Health Agency of Canada, with the involvement of others, including service providers and academics. Policy changes can create new inequities, so it is important to track a variety of measures regularly.

\section{Other guidelines}

The Chief Public Health Officer of Canada's report, From Risk to Resilience: An Equity Approach to COVID-19, describes approaches that overlap with our recommendations, including the Housing First intervention, harm reduction to reduce opioidrelated harms, and the prevention of intimate partner violence. ${ }^{1}$ The "Build Back Fairer" report outlines high-level strategies for addressing inequities in England in the wake of the COVID-19 pandemic. ${ }^{109}$ Other groups have made recommendations relevant to the pandemic recovery period on specific topics such as housing, ${ }^{110}$ with associated advocacy for "recovery for all" (www. recoveryforall.ca). Before the pandemic, a guideline made a similar strong recommendation for permanent supportive housing. ${ }^{111}$

\section{Gaps in knowledge}

For some changes or interventions, limited information was available about the resources needed for implementation, acceptability, feasibility and cost-effectiveness. Some interventions, such as cash transfers, were studied in mostly low- and middle-income countries, although they are relevant in highincome countries. Although interventions were selected on the basis that they would promote equity, it is not necessarily clear that they would be implemented in a fair and equitable fashion.

\section{Limitations}

The topics and research questions were selected by panel members who were all scientists; other groups could have chosen different topics and made different recommendations regarding the promotion of health equity. Our recommendations aimed at promoting health equity should not be viewed as exhaustive or definitive. We sometimes focus on individual-level services (e.g., eviction prevention) versus systemic change (e.g., eviction bans), although other approaches may have led to different recommendations based on the availability of studies. Some topics, such as the health of migrant workers or not-for-profit versus for-profit long-term care, were not explicitly included, although we recognized them as important. Other important topics, such as the health of Indigenous children, were included indirectly, although they could have independently comprised several recommendations as they do in cited documents, such as the final report of the Truth and Reconciliation Commission, which includes 5 relevant calls to action. ${ }^{95}$

Stakeholders suggested other topics such as child mental health; we considered these and performed literature searches but decided not to pursue them when it was not clear there were studied interventions that would promote health equity. Large issues such as homelessness will not be addressed by implementing only our small number of recommendations, aimed at specific populations; additional efforts will be needed, and some needed changes may not be supported by studies.

We relied on systematic reviews that were carried out before the pandemic, for the most part, and these could have excluded important studies published before and during the pandemic. Some of the interventions were studied in only some settings and may have been studied separately, whereas our recommendations are interrelated (e.g., improvements in income security may promote stable housing).

\section{Conclusion}

The pandemic recovery period represents an opportunity to address health inequities that have led to an unfair distribution of the burden and harms of COVID-19. Policy changes at the federal, provincial and municipal levels that promote health equity had been studied before this pandemic, and they should be implemented before the next one. The changes are in line with proclamations to address poverty from before the pandemic, and the prominent attention to inequities during the pandemic may facilitate change. The effects of these interrelated changes on health equity should be carefully measured to inform further policy changes in Canada and elsewhere.

\section{References}

1. From risk to resilience: an equity approach to COVID-19: the Chief Public Health Officer of Canada's report on the state of public health in Canada 2020. Ottawa: Public Health Agency of Canada; 2020.

2. Enhanced epidemiological summary: COVID-19 in Ontario - a focus on material deprivation. Toronto: Public Health Ontario:1-24.

3. Enhanced epidemiological summary: COVID-19 in Ontario - A Focus on Diversity. Toronto: Public Health Ontario; 2020:1-22.

4. Populations disproportionately impacted by COVID-19: current state assessment. City of Vancouver, Social Policy and Projects Research Team; 2021: 1-73. 
5. Richard L, Booth R, Rayner J, et al. Testing, infection and complication rates of COVID-19 among people with a recent history of homelessness in Ontario, Canada: a retrospective cohort study. CMAJ Open 2021;9:E1-9.

6. Gomes T, Kitchen SA, Murray R. Measuring the burden of opioid-related mortality in Ontario, Canada, during the COVID-19 pandemic. JAMA Netw Open 2021;4:e2112865.

7. Blair A, Parnia A, Siddiqi A. A time-series analysis of testing and COVID-19 outbreaks in Canadian federal prisons to inform prevention and surveillance efforts. Can Commun Dis Rep 2021;47:66-76.

8. Pandemic influenza preparedness and response: a WHO guidance document. Geneva: World Health Organization; 2009. Available: https://www.ncbi.nlm. nih.gov/books/NBK143062/ (accessed 2021 Mar. 3)

9. Best Brains Exchange proceedings report: Strengthening the structural determinants of health post-COVID-19. Ottawa: Public Health Agency of Canada; 2020; modified 2021 Mar. 16. Available: https://www.canada.ca/en/public-health/ corporate/publications/chief-public-health-officer-reports-state-public-health -canada/from-risk-resilience-equity-approach-covid-19/best-brains-exchange -proceedings-report.html (accessed 2021 Apr. 9).

10. COVID-19 in Canada: a one-year update on social and economic impacts. Cat no 11-631-x2021001. Ottawa: Statistics Canada; 2021 Mar. 11:1-52. Available: https:// www150.statcan.gc.ca/n1/pub/11-631-x/11-631-x2021001-eng.htm (accessed 2021 Nov. 12).

11. Schünemann H, Brożek J, Guyatt G, et al., editors. GRADE handbook. London (UK): GRADE Working Group; 2013. Available: https://gdt.gradepro.org/app/ handbook/handbook.html (accessed 2021 Mar. 4).

12. Pega F, Liu SY, Walter S, et al. Unconditional cash transfers for reducing poverty and vulnerabilities: effect on use of health services and health outcomes in lowand middle-income countries. Cochrane Database Syst Rev 2017;11:CD011135.

13. Results of Finland's basic income experiment: small employment effects, better perceived economic security and mental wellbeing. Helsinki (Finland): Kela; 2020. Available: https://www.kela.fi/web/en/news-archive/-/asset_publisher/ IN08GY2nlrZo/content/results-of-the-basic-income-experiment-small-employment -effects-better-perceived-economic-security-and-mental-wellbeing (accessed 2021 Mar. 3).

14. Salehi-Isfahani D, Mostafavi-Dehzooei MH. Cash transfers and labor supply: evidence from a large-scale program in Iran. J Dev Econ 2018;135:349-67.

15. Forget EL. New questions, new data, old interventions: the health effects of a guaranteed annual income. Prev Med 2013;57:925-8.

16. Baker AC, Martin-West S, Samra S, et al. Mitigating loss of health insurance and means tested benefits in an unconditional cash transfer experiment: implementation lessons from Stockton's guaranteed income pilot. SSM Popul Health 2020;11:100578.

17. Williams CE. Taking bold action on homelessness. Foundations for social change: New Leaf project. Vancouver: Foundations for Social Change; 2020:1-17. Available: https://static1.squarespace.com/static/5f07a92f21d34b403c788e05 /t/617989f9898f760c97fcbace/1635355131600/2021_FSC_Statement_of_ Impact_w_Expansion.pdf (accessed 2021 Nov. 12).

18. Delsen L, Schilpzand R. Individual preferences for the unconditional basic income in the European Union. In: Delsen L, editor. Empirical Research on an Unconditional Basic Income in Europe. Cham: Springer; 2019:29-60.

19. Mendelson M. Lessons from Ontario's basic income pilot. Maytree; 2019. Available: https://www.deslibris.ca/ID/10102735 (accessed 2021 Mar. 3).

20. Table 11-10-0066-01: Market Basket Measure (MBM) thresholds for the reference family by Market Basket Measure region, component and base year. Ottawa: Statistics Canada; modified 2021 Oct. 27. Available: https://www150. statcan.gc.ca/t1/tbl1/en/tv.action?pid=1110006601 (accessed 2021 Mar. 3).

21. Ammar N, Busby C, Ahmed SM. Distributional and fiscal analysis of a national guaranteed basic income. Ottawa: Office of the Parliamentary Budget Officer; 2021. Available: https://www.pbo-dpb.gc.ca/en/blog/news/RP-2122-001-S--distributional -fiscal-analysis-national-guaranteed-basic-income--analyse-financiere-distributive -un-revenu-base-garanti-echelle-nationale (accessed 2021 Apr. 9).

22. Renahy E, Mitchell C, Molnar A, et al. Connections between unemployment insurance, poverty and health: a systematic review. Eur J Public Health 2018;28:269-75.

23. Virtanen $P$, Liukkonen $V$, Vahtera J, et al. Health inequalities in the workforce: the labour market core-periphery structure. Int J Epidemiol 2003;32:1015-21.

24. O'Campo P, Molnar A, Ng E, et al. Social welfare matters: a realist review of when, how, and why unemployment insurance impacts poverty and health. Soc Sci Med 2015;132:88-94.

25. Jou J, Kozhimannil KB, Abraham JM, et al. Paid maternity leave in the United States: associations with maternal and infant health. Matern Child Health $J$ 2018;22:216-25.

26. Khan MS. Paid family leave and children health outcomes in OECD countries. Child Youth Serv Rev 2020;116:105259.

27. Piper K, Youk A, James AE III, et al. Paid sick days and stay-at-home behavior for influenza. PLoS One 2017;12:e0170698.
28. Canadians' opinions on possible key priorities for the federal budget. Project 2016798. CTV News/NANOS Survey. NANOS Research; 2016:1-17. Available: https:// www.nanos.co/wp-content/uploads/2017/07/2016-798A-CTV-February-Budget -and-the-Economy-Populated-Report-w-tabs-R.pdf (accessed 2021 Nov. 12).

29. Orton L, Pennington A, Nayak S, et al. Group-based microfinance for collective empowerment: a systematic review of health impacts. Bull World Health Organ 2016;94:694-704A.

30. Bhuiya A, Chowdhury M. Beneficial effects of a woman-focused development programme on child survival: evidence from rural Bangladesh. Soc Sci Med 2002; 55:1553-60.

31. Lorenzetti LMJ, Leatherman S, Flax VL. Evaluating the effect of integrated microfinance and health interventions: an updated review of the evidence. Health Policy Plan 2017;32:732-56.

32. Financial information. Washington (DC): Grameen Foundation. Available: https:// grameenfoundation.org/partners/resources/financial-information (accessed 2021 Mar. 3).

33. Lall P, Shaw SA, Saifi R, et al. Acceptability of a microfinance-based empowerment intervention for transgender and cisgender women sex workers in Greater Kuala Lumpur, Malaysia. J Int AIDS Soc 2017;20:21723.

34. Payday loans: market trends. Ottawa: Financial Consumer Agency of Canada; 2016:1-20. Available: https://www.canada.ca/en/financial-consumer-agency/ programs/research/payday-loans-market-trends.html (accessed 2021 Nov. 12).

35. Dijkema B. The changing face of payday lending in Canada. Hamilton (ON): Cardus; 2019. Available: https://www.cardus.ca/research/work-economics/reports/the -changing-face-of-payday-lending-in-canada/ (accessed 2021 Nov. 12).

36. Khandker SR, Khalily MAB, Samad HA. Beyond ending poverty: the dynamics of microfinance in Bangladesh. Washington (DC): World Bank; 2016. Available: https://openknowledge.worldbank.org/handle/10986/24669 (accessed 2021 Nov. 12).

37. Aubry T, Bloch G, Brcic V, et al. Effectiveness of permanent supportive housing and income assistance interventions for homeless individuals in high-income countries: a systematic review. Lancet Public Health 2020;5:e342-60.

38. Hwang SW, Tolomiczenko G, Kouyoumdjian FG, et al. Interventions to improve the health of the homeless: a systematic review. Am J Prev Med 2005;29:311-9.

39. Goering P, Veldhuizen S, Nelson GB, et al. Further validation of the pathways housing first fidelity scale. Psychiatr Serv 2016;67:111-4.

40. Nelson G, Patterson M, Kirst M, et al. Life changes among homeless persons with mental illness: a longitudinal study of housing first and usual treatment. Psychiatr Serv 2015;66:592-7.

41. Piat M, Seida K, Padgett D. Choice and personal recovery for people with serious mental illness living in supported housing. J Ment Health 2020;29:306-13.

42. Latimer EA, Rabouin D, Cao Z, et al.; At Home/Chez Soi Investigators. Costeffectiveness of housing first with assertive community treatment: results from the Canadian At Home/Chez Soi trial. Psychiatr Serv 2020;71:1020-30.

43. Holl M, van den Dries L, Wolf JRLM. Interventions to prevent tenant evictions: a systematic review. Health Soc Care Community 2016;24:532-46.

44. Seron C, Ryzin GG, Frankel MM, et al. The impact of legal counsel on outcomes for poor tenants in New York City's housing court: results of a randomized experiment. Law Soc Rev 2001;35:419-34.

45. Evans G. AcAteer M. Does debt advice pay? A business case for social landlords final report. London (UK): The Financial Inclusion Centre; 2011:1-93. Available: http://inclusioncentre.co.uk/wordpress29/wp-content/uploads/2011/12/Does _Debt-Advice_Pay_A-Business_Case_for_Social_Landlords_Final_Report.pdf (accessed 2021 Nov. 12).

46. Rivas C, Ramsay J, Sadowski L, et al. Advocacy interventions to reduce or eliminate violence and promote the physical and psychosocial well-being of women who experience intimate partner abuse. Cochrane Database Syst Rev 2015;(12):CD005043.

47. Rodriguez MA, Bauer HM, McLoughlin E, et al. Screening and intervention for intimate partner abuse: practices and attitudes of primary care physicians. JAMA 1999;282:468-74.

48. Wadsworth P, Kothari C, Lubwama G, et al. Health and health care from the perspective of intimate partner violence adult female victims in shelters: impact of IPV, unmet needs, barriers, experiences, and preferences. Fam Community Health 2018;41:123-33.

49. Martinez $O$, Boles J, Muñoz-Laboy M, et al. Bridging health disparity gaps through the use of medical legal partnerships in patient care: a systematic review. J Law Med Ethics 2017;45:260-73.

50. Edwards R. Staying home, leaving violence: promoting choices for women leaving abusive partners. Sydney (AU): Australian Domestic and Family Violence Clearinghouse; 2004.

51. Karakurt G, Koç E, Çetinsaya EE, et al. Meta-analysis and systematic review for the treatment of perpetrators of intimate partner violence. Neurosci Biobehav Rev 2019;105:220-30. 
52. Brown TW, van Urk FC, Waller R, et al. Centre-based day care for children younger than five years of age in low- and middle-income countries. Cochrane Database Syst Rev 2014;(9):CD010543.

53. van Urk FC, Brown TW, Waller R, et al. Centre-based day care for children younger than five years of age in high-income countries. Cochrane Database Syst Rev 2014;(9):CD010544

54. Toroyan T, Roberts I, Oakley A, et al. Effectiveness of out-of-home day care for disadvantaged families: randomised controlled trial. BMJ 2003;327:906.

55. Carlin C, Davis EE, Krafft C, et al. Parental preferences and patterns of child care use among low-income families: a Bayesian analysis. Child Youth Serv Rev 2019;99:172-85.

56. Muennig P, Schweinhart L, Montie J, et al. Effects of a prekindergarten educational intervention on adult health: 37-year follow-up results of a randomized controlled trial. Am J Public Health 2009;99:1431-7.

57. Kristjansson E, Francis DK, Liberato S, et al. Food supplementation for improving the physical and psychosocial health of socio-economically disadvantaged children aged three months to five years. Cochrane Database Syst Rev 2015;2015:CD009924.

58. Colley P, Myer B, Seabrook J, et al. The impact of Canadian school food programs on children's nutrition and health: a systematic review. Can J Diet Pract Res 2019;80:79-86.

59. Hunger Report 2020: the impact of COVID-19 on food bank use in Ontario. Toronto: Feed Ontario; 2020. Available: https://feedontario.ca/hunger-report-2020/ (accessed 2021 Mar. 3).

60. Grantham-McGregor S. Can the provision of breakfast benefit school performance? Food Nutr Bull 2005;26(Suppl 2):S144-58.

61. Mattick RP, Breen C, Kimber J, et al. Methadone maintenance therapy versus no opioid replacement therapy for opioid dependence. Cochrane Database Syst Rev 2009;(3):CD002209.

62. Marshall BDL, Milloy M-J, Wood E, et al. Reduction in overdose mortality after the opening of North America's first medically supervised safer injecting facility: a retrospective population-based study. Lancet 2011;377:1429-37.

63. Magwood O, Salvalaggio G, Beder M, et al. The effectiveness of substance use interventions for homeless and vulnerably housed persons: a systematic review of systematic reviews on supervised consumption facilities, managed alcohol programs, and pharmacological agents for opioid use disorder. PLoS One 2020;15:e0227298.

64. Platt L, Minozzi S, Reed J, et al. Needle and syringe programmes and opioid substitution therapy for preventing HCV transmission among people who inject drugs: findings from a Cochrane Review and meta-analysis. Addiction 2018;113:545-63.

65. Larance B, Degenhardt L, Grebely J, et al. Perceptions of extended-release buprenorphine injections for opioid use disorder among people who regularly use opioids in Australia. Addiction 2020;115:1295-305.

66. Lange BCL, Bach-Mortensen AM. A systematic review of stakeholder perceptions of supervised injection facilities. Drug Alcohol Depend 2019;197:299-314.

67. Opioids in Canada: one-in-eight have family or close friends who faced addiction. Vancouver: Angus Reid Institute; 2018. Available: https://angusreid.org/ opioid-crisis/ (accessed 2021 Sept. 28).

68. Ontario Drug Policy Research Network; Office of the Chief Coroner for Ontario/ Ontario Forensic Pathology Service; Public Health Ontario; Centre on Drug Policy Evaluation. Preliminary patterns in circumstances surrounding opioid-related deaths in Ontario during the COVID-19 pandemic. Toronto: Public Health Ontario; 2020:1-24. Available: https://www.publichealthontario.ca/-/media/documents/o /2020/opioid-mortality-covid-surveillance-report.pdf?la=en (accessed 2021 Nov. 12).

69. Illicit drug toxicity deaths in BC: January 1, 2011-January 31, 2021. Burnaby (BC): Office of the Chief Coroner; 2021:1-26. Available: https://www2.gov.bc.ca/ assets/gov/birth-adoption-death-marriage-and-divorce/deaths/coroners-service /statistical/illicit-drug.pdf (accessed 2021 Nov. 12).

70. Norton A, Kerr T. Applying the lessons of COVID-19 response to Canada's worsening opioid epidemic. EClinicalMedicine 2020;29:100633.

71. Simões D, Stengaard AR, Combs L, et al.; EuroTEST COVID-19 impact assessment consortium of partners. Impact of the COVID-19 pandemic on testing services for HIV, viral hepatitis and sexually transmitted infections in the WHO European Region, March to August 2020. Euro Surveill 2020;25:2001943.

72. Pottie K, Medu O, Welch V, et al. Effect of rapid HIV testing on HIV incidence and services in populations at high risk for HIV exposure: an equity-focused systematic review. BMJ Open 2014;4:e006859.

73. Grad R, Thombs B, Tonelli M, et al.; Canadian Task Force on Preventive Health Care. Recommendations on hepatitis C screening for adults. CMAJ 2017;189:E594-604.

74. Chou R, Dana T, Grusing S, et al. Screening for HIV infection in asymptomatic, nonpregnant adolescents and adults: updated evidence report and systematic review for the US Preventive Services Task Force. JAMA 2019;321:2337-48.

75. Hawk ME, Chung A, Creasy SL, et al. A scoping review of patient preferences for HIV self-testing services in the United States: implications for harm reduction. Patient Prefer Adherence 2020;14:2365-75.

76. Bert F, Gualano MR, Biancone P, et al. Cost-effectiveness of HIV screening in high-income countries: a systematic review. Health Policy 2018;122:533-47.
77. Malta M, Varatharajan T, Russell C, et al. Opioid-related treatment, interventions, and outcomes among incarcerated persons: a systematic review. PLoS Med 2019;16:e1003002.

78. Kinlock TW, Gordon MS, Schwartz RP, et al. A randomized clinical trial of methadone maintenance for prisoners: results at 12 months postrelease. J Subst Abuse Treat 2009;37:277-85.

79. Hedrich D, Alves $P$, Farrell $M$, et al. The effectiveness of opioid maintenance treatment in prison settings: a systematic review. Addiction 2012;107:501-17.

80. Larney S, Zador D, Sindicich N, et al. A qualitative study of reasons for seeking and ceasing opioid substitution treatment in prisons in New South Wales, Australia. Drug Alcohol Rev 2017;36:305-10.

81. Horn BP, Li X, Mamun S, et al. The economic costs of jail-based methadone maintenance treatment. Am J Drug Alcohol Abuse 2018;44:611-8.

82. Kesselheim AS, Huybrechts KF, Choudhry NK, et al. Prescription drug insurance coverage and patient health outcomes: a systematic review. Am J Public Health 2015;105:e17-30.

83. Raebel MA, Delate T, Ellis JL, et al. Effects of reaching the drug benefit threshold on Medicare members' healthcare utilization during the first year of Medicare Part D. Med Care 2008;46:1116-22.

84. Persaud N, Bedard M, Boozary A, et al. Adherence at 2 years with distribution of essential medicines at no charge: The CLEAN Meds randomized clinical trial. PLoS Med. 2021 May 1;18(5):e1003590.

85. Access for all: near universal support for a pharmacare plan covering Canadians' prescription drug costs. Vancouver: Angus Reid Institute; 2020. Available: https://angusreid.org/pharmacare-2020/ (accessed 2021 Mar. 3).

86. Labour Force Survey, January 2021. Ottawa: Statistics Canada; 2021, modified 2021 Feb. 5. Available: https://www150.statcan.gc.ca/n1/daily-quotidien/210205/ dq210205a-eng.htm (accessed 2021 Mar. 4).

87. Casey B. Pharmacare now: prescription medicine coverage for all Canadians. 42nd Parliament, 1st sess. Ottawa: House of Commons; 2018:1-140.

88. Advisory Council on the Implementation of National Pharmacare. Ottawa: Health Canada; modified 2018 July 2. Available: https://www.canada.ca/en/health -canada/corporate/about-health-canada/public-engagement/external-advisory -bodies/implementation-national-pharmacare.html (accessed 2021 Mar. 3).

89. Malanik C. Federal cost of a national pharmacare program. Ottawa: Office of the Parliamentary Budget Officer; 2017. Available: https://www.pbo-dpb.gc. ca/en/blog/news/Pharmacare (accessed 2021 Mar. 3).

90. Paradies Y, Ben J, Denson N, et al. Racism as a determinant of health: a systematic review and meta-analysis. PLoS One 2015;10:e0138511.

91. Gee GC, Ford CL. Structural racism and health inequities: old issues, new directions. Du Bois Rev 2011;8:115-32.

92. Williams DR, Cooper LA. Reducing racial inequities in health: using what we already Inow to take action. Int J Environ Res Public Health 2019;16:606.

93. Bailey ZD, Krieger N, Agénor M, et al. Structural racism and health inequities in the USA: evidence and interventions. Lancet 2017;389:1453-63.

94. Guyatt GH, Alonso-Coello P, Schünemann HJ, et al. Guideline panels should seldom make good practice statements: guidance from the GRADE Working Group. J Clin Epidemiol 2016;80:3-7.

95. Honouring the truth, reconciling for the future: summary of the final report of the Truth and Reconciliation Commission of Canada. Ottawa: Truth and Reconciliation Commission of Canada; 2015. Available: https://publications.gc.ca/collections/ collection_2015/trc/IR4-7-2015-eng.pdf (accessed 2021 Nov. 12).

96. Special Rapporteur on the rights of Indigenous peoples. Geneva: Office of the United Nations High Commissioner for Human Rights (OHCHR). Available: https:// www.ohchr.org/en/issues/ipeoples/srindigenouspeoples/pages/sripeoplesindex. aspx (accessed 2021 Mar. 3).

97. Reclaiming power and place: the final report of the national inquiry into missing and murdered Indigenous women and girls. National Inquiry to Missing and Murdered Indigenous Women and Girls; 2019. Available: https://www. mmiwg-ffada.ca/final-report/ (accessed 2021 Mar. 3).

98. Report of the Working Group of Experts on People of African Descent on its mission to Canada. United Nations General Assembly; 2017:1-20.

99. Lewis S. Report of the advisor on race relations to the Premier of Ontario, Bob Rae. Mississauga (ON): Special Investigations Unit; 1992. Available: https://www. siu.on.ca/pdfs/report_of_the_advisor_on_race_relations_to_the_premier_of_ ontario_bob_rae.pdf (accessed 2021 Nov. 12).

100. Justice for Joyce: public reports and evidence briefs. Toronto: Well Living House; 2020. Available: www.welllivinghouse.com/justice-for-joyce-public -reports-and-evidence-briefs/ (accessed 2021 Sept. 28).

101. Williamson EJ, Walker AJ, Bhaskaran K, et al. Factors associated with COVID19-related death using OpenSAFELY. Nature 2020;584:430-6.

102. Brouwers MC, Kho ME, Browman GP, et al.; AGREE Next Steps Consortium. AGREE II: advancing guideline development, reporting and evaluation in health care. CMAJ 2010;182:E839-42. 
103. Key health inequalities in Canada: a national portrait - executive summary. Ottawa: Public Health Agency of Canada; modified 2018 Nov. 14. Available: https://www. canada.ca/en/public-health/services/publications/science-research-data/key-health -inequalities-canada-national-portrait-executive-summary.html (accessed 2021 Aug. 10).

104. Social determinants of health. Geneva: World Health Organization. Available: https://www.who.int/westernpacific/health-topics/social-determinants-of-health (accessed 2021 Aug. 10).

105. Moberg J, Oxman AD, Rosenbaum S, et al.; GRADE Working Group. The GRADE Evidence to Decision (EtD) framework for health system and public health decisions. Health Res Policy Syst 2018;16:45.

106. Schünemann HJ, Al-Ansary LA, Forland F, et al.; Board of Trustees of the Guidelines International Network. Guidelines International Network: principles for disclosure of interests and management of conflicts in guidelines. Ann Intern Med 2015;163:548-53.
107. Traversy G, Barnieh L, Akl EA, et al. Managing conflicts of interest in the development of health guidelines. CMAJ 2021;193:E49-54.

108. Canada's First Poverty Reduction Strategy. Employment and Social Development Canada; modified 2021 May 20. Available: https://www.canada.ca/en/employment -social-development/programs/poverty-reduction/reports/strategy.html (accessed 2021 Aug. 10).

109. Marmot M, Allen J, Goldblatt P, et al. Build Back Fairer: the COVID-19 Marmot review - the pandemic, socioeconomic and health inequalities in England. London (UK): Institute of Health Equity; 2020.

110. Turnbull J, Baral S, Bond A, et al. Seeking shelter: homelessness and COVID-19. Ottawa: Royal Society of Canada; 2021.

111. Pottie K, Kendall CE, Aubry T, et al. Clinical guideline for homeless and vulnerably housed people, and people with lived homelessness experience. CMAJ 2020;192:E240-54.
Competing interests: Nav Persaud reports being a member of the Canadian Task Force on Preventive Health Care (travel expenses paid for the Public Health Agency of Canada [PHAC]), and being an unpaid adviser to the pan-Canadian Advisory Panel on a Framework for a Prescription Drug List. Dr. Persaud also reports receiving grants from the Canadian Institutes of Health Research (CIHR), Canada Research Chairs Program, and the Ontario Strategy for Patient-Oriented Research (SPOR) SUPPORT Unit. James Dunn reports receiving personal fees from the City of Toronto (Toronto Public Health) for research on policy options for healthy housing. Stephen Hwang reports serving on the Board of Directors for Good Shepherd Ministries (volunteer, unpaid role), being Chair of the Data Safety Monitoring Board for the Inspire Quitting Study (funded by the National Cancer Institute, National Institutes of Health [volunteer, unpaid role]), and being a member of the Research Committee for the National Health Care for the Homeless Council (volunteer, unpaid role). Dr. Hwang also reports receiving fees as the principal investigator (PI) on a CIHR Foundations Grant for Interventions Research in Homelessness, Housing and Health, and as PI on a CIHR Operating Grant for a COVID-19 cohort study of people experiencing homelessness in Toronto. Dr. Hwang reports receiving fees as a health care provider for Inner City Health Associates (funded by the Ontario Ministry of Health). Jonathon Maguire reports receiving grants from the Canadian Institutes of Health Research (CIHR), and the Ontario Strategy for Patient-Oriented Research (SPOR) Support Unit. Andrew Pinto reports serving on the Advisory Board of the Alliance for Healthier Communities, and being an unpaid advisor to Muto Health Solutions. Dr. Pinto also reports receiving grants from CIHR; the Ontario government, including the Ministry of Health and Long-Term Care; the PSI Foundation; the Maytree Foundation; the Atkinson Foundation; the Metcalf Foundation; the St. Michael's Hospital Foundation; and the Ontario SPOR SUPPORT Unit. Dr. Pinto has received honoraria for presentations at the Joint Centre for Bioethics, the University of Toronto (2019), McMaster University (2020) and the University of Ghent (2020). Dr. Pinto reports receiving salary support from the following: Department of Family and Community Medicine, St. Michael's Hospital; Department of Family and Community Medicine, Faculty of Medicine, University of Toronto; and the Li Ka Shing Knowledge Institute, St. Michael's Hospital. Dr. Pinto was the recipient of the 2019 PSI Graham Farquharson Knowledge Translation Fellowship. Patricia O'Campo reports being the Board Chair for the United Way of Greater Toronto, which funds agencies serving women living with intimate partner violence. Dr. O'Campo also reports receiving funding from CIHR as the Canada Research Chair in Population Health Interventions, and from the Social Sciences and Humanities Research Council for 2 grants concerning domestic violence. Sean Rourke reports receiving consulting fees as expert advisor for strategic implementation from the Canadian Foundation for AIDS Research. Dr. Rourke also reports receiving grants from CIHR and PHAC, paid to St. Michael's Hospital, and grant support from the Annual Foundation, paid to the Canadian Foundation for AIDS Research (no payments to Dr. Rourke). Daniel Werb reports receiving support from CIHR via a New Investigator Salary Award and from the St. Michael's Hospital Foundation. Dr. Werb is also named on a pending patent for a drug-checking device. No other competing interests were declared.

This article has been peer reviewed.

Affiliations: MAP Centre for Urban Health Solutions (Persaud, Wood, Workentin, Adekoya, Dunn, Hwang, Maguire, Pinto, O'Campo, Rourke, Werb), St. Michael's Hospital, Unity Health Toronto; Faculty of Medicine (Persaud, Hwang, Maguire, Pinto), and Department of Psychiatry (Rourke), Faculty of Medicine, University of Toronto, Toronto, Ont.

Contributors: All authors are the members of the recommendations panel involved in the guideline development process. Nav Persaud contributed to conception and design of the work, interpretation of the data, drafted the manuscript and revised it critically for important intellectual content. Hannah Woods and Aine Workentin contributed to acquisition and interpretation of the data, drafted the manuscript and revised it critically for important intellectual content. Itunu Adekoya contributed to acquisition and interpretation of data. James Dunn, Stephen Hwang, Jonathon Maguire, Andrew Pinto, Patricia O'Campo, Sean Rourke and Daniel Werb contributed to design, interpretation, drafting of the manuscript and revising it critically for important intellectual content. All authors gave final approval of the version to be published and agreed to be accountable for all aspects of the work.

Funding: The guideline process was supported by funding from the St. Michael's Hospital Foundation which was not involved in the conception, development or communication of the recommendations.

Endorsements: This guideline is endorsed by Black Physicians of Canada, Canadian Doctors for Medicare and the Canadian Medical Association. The College of Family Physicians of Canada supports these recommendations.

Content licence: This is an Open Access article distributed in accordance with the terms of the Creative Commons Attribution (CC BY-NC-ND 4.0) licence, which permits use, distribution and reproduction in any medium, provided that the original publication is properly cited, the use is noncommercial (i.e., research or educational use), and no modifications or adaptations are made. See: https://creativecommons.org/licenses/by-nc-nd/4.0/

Data sharing: All of the data are available in the article and appendices.

Acknowledgements: The authors thank Janet Brown, Pamela McDonaldKuhne and Suzanne Zerger for support of the guideline process including stakeholder engagement. They also thank Carolyn Zeigler for assistance with literature searches.

Disclaimer: Nav Persaud is an associate editor for CMAJ and was not involved in the editorial decision-making process for this article.

Correspondence to: Nav Persaud, nav.persaud@utoronto.ca 